\title{
PROGRAM IBU HAMIL SEHAT KECAMATAN SINGAPARNA KABUPATEN TASIKMALAYATAHUN 2017
}

\section{A. DASAR PEMIKIRAN}

Kesehatan ibu hamil adalah salah satu aspek yang penting untuk diperhatikan dalam siklus kehidupan seorang perempuan karena sepanjang masa kehamilannya dapat terjadi komplikasi yang tidak diharapkan. Setiap ibu hamil akan menghadapi risiko yang bisa mengancam jiwanya. Oleh karena itu, setiap ibu hamil memerlukan asuhan selama masa kehamilannya (Salmah, 2006). Angka kematian ibu (AKI) merupakan salah satu indikator untuk melihat derajat kesehatan suatu negara. Jumlah kematian ibu di negara berkembang tergolong tinggi seperti yang terjadi di Afrika Sub Sahara dan Asia Selatan (WHO, 2013).

Salah satu upaya yang dilakukan Departemen Kesehatan dalam rangka mempercepat penurunan angka kematian ibu adalah pelayanan kesehatan maternal yang berkualitas, yaitu melakukan pemeriksaan kehamilan atau Antenatal Care (ANC). Tujuan dari ANC adalah untuk menjaga agar ibu hamil dapat melalui masa kehamilan, persalinan dan nifas dengan baik dan selamat, serta menghasilkan bayi yang sehat (Depkes RI, 2014). Menurut Manuaba 2010 tujuan dilakukan pemeriksaan kehamilan adalah untuk memantau kemajuan kehamilan, memastikan kehamilan ibu dan tumbuh kembang janin, meningkatkan dan mempertahankan kesehatan fisik, mental, dan sosial ibu, mengenali secara dini adanya komplikasi yang mungkin terjadi selama masa kehamilan termasuk riwayat penyakit secara umum dan pembedahan, mempersiapkan persalinan cukup bulan dan persalinan yang normal, mempersiapkan ibu agar masa nifas berjalan normal dan pemberian ASI ekslusif, mempersiapkan peran ibu dan keluarga dalam menerima kelahiran bayi agar dapat tumbuh kembang secara optimal dan menurunkan angka kesakitan dan kematian ibu dan perinatal.

STIKes Respati sebagai satu satunya sekolah tinggi ilmu kesehatan di Kabupaten Tasikmalaya memiliki tanggung jawab untuk memberikan kontribusi terhadap permasalahan terkait kesehatan di Kabupaten Tasikmalaya melalui kegiatan Tri Dharma Perguruan Tinggi yaitu dengan kegiatan pengabdian masyarakat. Salah satu upaya nyata STIKes Respati adalah melaksanakan kegiatan pengabdian masyarakat dengan tema "Program Ibu Hamil Sehat" sebagai upaya untuk meningkatkan kesehatan ibu hamil dan dengan kegiatan itu sebagai deteksi dini komplikasi pada ibu hamil.

B. TUJUAN

Untuk melakukan kegiatan Program Ibu Hamil Sehat sebagai upaya meningkatkan kesehatan ibu hamil dan untuk deteksi dini komplikasi pada ibu hamil

\section{BENTUK KEGIATAN} adalah :

Adapun bentuk kegiatan ini

1. Pemeriksaan ibu hamil

Pemeriksaan ibu hamil yang dilakukan meliputi pemeriksaan fisik dan pemeriksaan laboratorium. Tidak itu saja tetapi kami bekerja sama dengan rumah sakit ibu dan 
anak Respati untuk bisa memfasilitasi pemeriksaan USG jika terdapat ibu hamil yang bermasalah baik itu pada ibu dan juga pada bayinya.

2. Lomba ibu hamil

Lomba ibu hamil diikuti oleh seluruh ibu hamil yang telah dilakukan pemeriksaan. Dalam lomba ibu hamil ada beberapa kriteria untuk menilai apakah ibu hamil tersebut dikategorikan sebagai ibu hamil sehat. Beberapa kategori diantarannya adalah :

a. Umur ibu hamil. Penilaian dari umur ibu hamil adalah apakah umur ibu hamil termasuk kategori umur beresiko $(<20$ tahun dan $>35$ tahun) dan apakah umur ibu hamil termasuk dalam usia reproduksi sehat $(20-35$ tahun)

b. Jumlah anak. Penilaian dari kategori jumlah anak adalah apakah ibu mempunyai anak lebih dari 2 dan kurang dari 2

c. Jarak kehamilan. Penilaian dari kategori jarak kehamilan adalah apakah jarak kehamilan sebelumnya kurang dari 2 tahun dan lebih dari 2 tahun

d. Kunjungan kehamilan. Penilaian dari kategori kunjungan kehamilan adalah apakah kunjungan/pemeriksaan kehamilan sesuai dengan usia kehamilannya dan sebaliknya

e. Status gizi ibu hamil. Penilaian dari ketegori status gizi ibu hamil adalah apakah status gizi baik jika dilihat dari pengukuran LILA $(\geq 23,5 \mathrm{~cm})$ dan kurang jika LILA $(<23,5 \mathrm{~cm})$

f. Pola konsumsi tablet Fe. Penilaian dari kategori pola konsumsi tablet fe adalah apakah ibu mengkonsumsi tablet fe dengan baik atau ibu mengkonsumsi tablet fe secara kurang baik

g. P4K. Penilaian dari kategori P4K adalah dilihat dari apakah $\mathrm{P} 4 \mathrm{~K}$ terisi dan dimengerti atau $\mathrm{P} 4 \mathrm{~K}$ tidak diisi dan tidak dimengerti

h. Pengetahuan ibu hamil tentang kehamilan. Penilaian dari kategori pengetahuan ibu hamil tentang kehamilan adalah baik, cukup dan kurang

\section{SASARAN}

Adapun sasaran dalam kegiatan ini adalah ibu hamil yang berada di wilayah Desa Cikunir Kecamatan Singaparna dengan rincian sebagai berikut :

1. Peserta ibu hamil yang melakukan pemeriksaan sebanyak 42 orang

2. Peserta ibu hamil yang mengikuti lomba ibu hamil berjumlah 41 orang

\section{E. TEMPAT DAN WAKTU}

Kegiatan dilaksanakan di Ruang Laboratorium kebidanan dan Aula STIKes Respati yang dilaksanakan hari senin tanggal 27 November 2017.

\section{F. KEPANITIAAN}

Kegiatan dilaksanakan oleh Dosen Program Studi Kebidanan serta oleh mahasiswa STIKes Respati. Adapun pelaksana kegiatan tersebut adalah :

1. Tupriliany Danefi, SST.,M.Kes

2. Widya Maya Ningrum, SST.,M.Kes

3. Lilis Lisnawati, SST.,M.Keb

4. Mahasiswa Kebidanan tingkat II 


\section{G. HASIL KEGIATAN}

Kegiatan ini meliputi :

1. Pemeriksaan kehamilan

Pemeriksaan ini mencakup pemeriksaan ante natal care. Hasil pemeriksaan menunjukan dari 50 orang ibu hamil yang diperiksa terdapat 4 orang ibu hamil mengalami Kekurangan energy Kronik (KEK) dan 15 orang ibu hamil dengan anemia sedang.

2. Lomba ibu hamil sehat

Lomba ibu hamil sehat dengan indicator penilaian : Kunjungan kehamilan, umur, jumlah anak, status gizi, pola konsumsi dan pengetahuan ibu hamil.

Tim penilaian adalah Bidan Desa, Bidan Puskesmas Singaparna dan dosen tetap STIKes Respati.

Pemenang lomba ini adalah :

Juara I : Ny. Nunung (Kampung Katubang)

Juara II : Ny. Nena (Cidamar)

Juara III : Ny. Ratna (Sindangreret)

3. Penyuluhan tentang sehat selama masa kehamilan

Penyuluhan dilaksanakan oleh tim dosen dengan materi pentingnya nutrisi selama masa kehamilan.

4. Pemeriksaan USG gratis

Program pemeriksaan USG gratis terselenggara atas kerjasama dengan Rumah Sakit Ibu dan Anak. Voucher USG gratis diperuntukan bagi ibu hamil dengan indikasi atau ibu hamil dengan trimester ketiga.

\section{H. DOKUMENTASI}

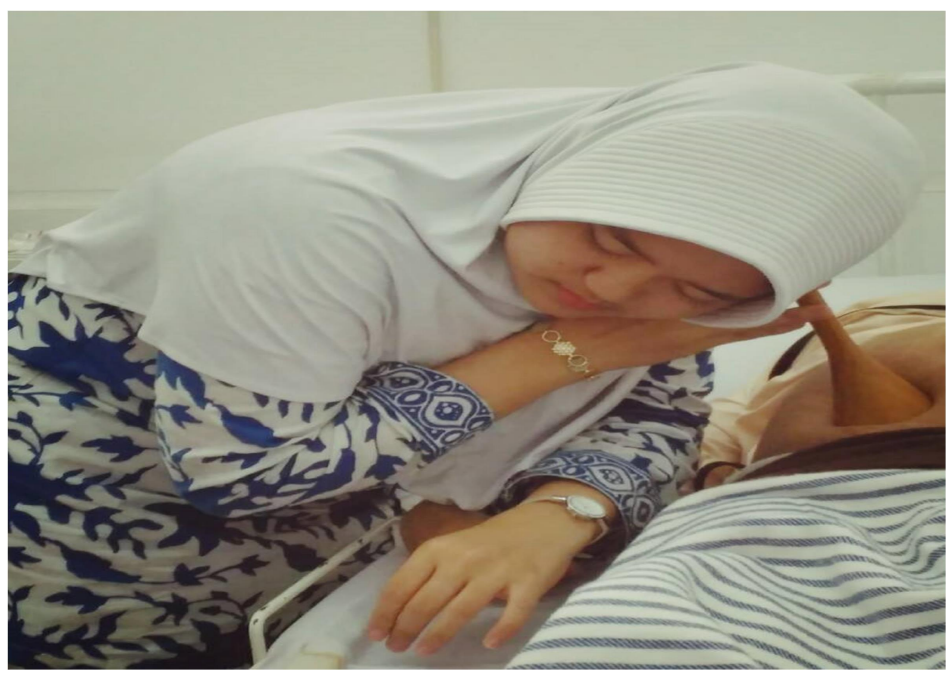

Pemeriksaan kehamilan 


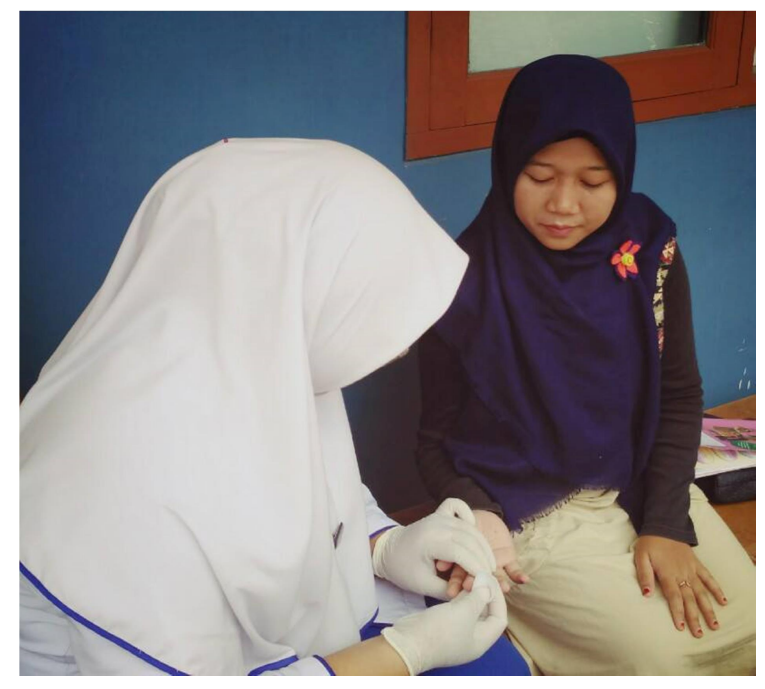

Pemeriksaan HB

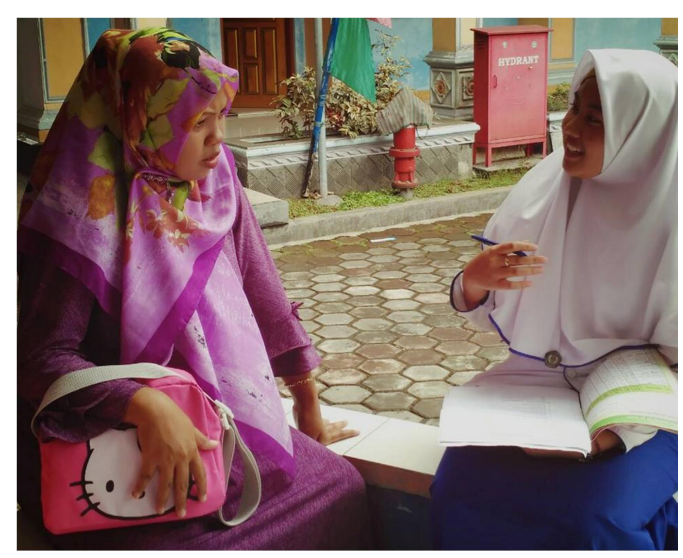

Konseling Kehamilan 